\title{
Population Status and Nesting Behavior of Red-Headed Vultures (Sarcogyps Calvus) at Dhorfirdi, Tanahun District, Nepal
}

\author{
Sandhya Manandhar ${ }^{1}$, Tej Kumar Shrestha ${ }^{1,2^{*}}$, Bijay Maharjan ${ }^{3}$, Anish Parajuli ${ }^{1}$ \\ ${ }^{l}$ Lumbini Environmental Services Pvt. Ltd., Kathmandu, Nepal. \\ ${ }^{2}$ Khwopa College, Dekocha, Bhaktapur, Nepal. \\ ${ }^{3}$ Suri Khola Hydropower Limited, Kathmandu, Nepal.
}

*Corresponding Author: Tej Kumar Shrestha, Lumbini Environmental Services Pvt. Ltd., Kathmandu, Nepal.

\begin{abstract}
Vultures are the natural cleaners of environment as they consume the carcasses of dead animals. The project aims to determine population status of vulture and nesting behavior of Red-headed vulture (Sarcogyps calvus).

Gyps himalayensis, Gyps fulvus, Neophron percnopterus, Gyps bengalensis, Gyps tenuirostris and Sarcogyps calvus were the six species of vultures sighted at Dhorfirdi in Millennium Trekking Route. G. himalayensis was found to be highest in number (27) in summer whereas G. fulvus was found to be highest in number (18) in winter. Study was conducted on nesting behavior of S. calvus. Both adults took turns in incubating, with one relieving the other at the nest. The change of shift occured twice a day i.e. in the morning and in the afternoon. The activities during incubation of vulture were head movement, resting, preening, change of shift, turning of egg and others. However, the major behaviors observed during incubation were head movement, resting and preening.
\end{abstract}

Keywords: Vulture, Sarcogyps calvus, Nesting behavior, Incubation, Millennium Trekking Route.

\section{INTRODUCTION}

Vultures are the largest flying raptors in Nepal with a crucial ecological role in the ecosystem via consumption of animal carcasses (Khadka \& Mandal, 2013). Globally, there are 23 species of vultures which has been classified as old world and new world vultures (IUCN, 2016; Poudel et al., 2014; Jerath et al., 2015-16). Old world vultures are of 16 species and are found in Africa, Asia and Europe (Poudel et al., 2014). All Nine species of vultures found in South Asian Region (IUCN, 2016) are recorded in Nepal (Poudel et al., 2014) out of which six species are resident, two species are migrants and one species is vagrant (DNPWC/MoFSC/GoN, 2009; Khadka \& Mandal, 2013). Out of nine species, four are listed as critically endangered by IUCN's Red List which includes White-rumped vulture (Gyps bengalensis), Indian vulture (Gyps indicus), Slender-billed vulture (Gyps tenuirostris) and Red-headed vulture (Sarcogyps calvus) (IUCN, 2016).

Vultures consume the carcasses of dead animals keeping the surrounding environment pollution and disease free; they are the natural cleaners of environment (Poudel et al., 2014). Vultures eat as well as digest meat in any stage of decay (IUCN, 2016). They are monogamous and colonial breeders. Their reproductive success depends on the breeding biology that includes the breeding habitat and breeding strategy. The breeding behavior includes aerial displays, nest site selection and defense, courtship and copulation, nest building, brooding and food provisioning to the chick. The first stage of breeding is nestbuilding. Vultures may build nests on cliffs, trees as well as old monuments and buildings (Kanaujia \& Kushwaha, 2013).

Vultures reproduce from the age of five to seven years. Except Lammergeier vulture (Gypaetus barbatus) and Egyptian vulture (Neophron percnopterus), the vultures lay only one egg in a year. Nest preparation 
starts from the month of September/October and incubation takes place for about seventy five days. Juvenile will be ready to fly after three months of hatching. Thus, the breeding season will start from the month of September/October and juvenile will be able to fly in the month of May/June (Poudel et al., 2014).

Bird Conservation Nepal - Royal Society for the Protection of Birds (BCN-RSPB) initiated an integrated approach for the conservation of vultures, which involves advocacy, education, monitoring, research, captive breeding, supplementary feeding and site protection to help implement Vulture Conservation Action Plans (2015-2019). In 2008, a Vulture Conservation Breeding Centre was established in Chitwan National Park, BCN-RSPB pioneered the idea of working with local communities to establish Vulture Safe Feeding Sites (VSFS) (Paudel et. al., 2016). VSFS take in old and ailing cattle from local farmers and care animals without the use of vulture-toxic Non-Steroidal Anti-inflammatory Drugs (NSAIDs), until their natural death and then provide their carcasses to vultures (Bhusal, 2018; Poudel et al., 2016). The catastrophic decline of vultures across Asia brought all the stakeholders at one place for developing strategic framework to address the issue and a consortium for Saving Asia's Vultures from Extinction (SAVE) which was established in 2011 (IUCN, 2016).

The study of nesting behavior of S. calvus has not been found till now. Also, there has not been any study conducted on the population status and nesting behavior of S. calvus at Dhorfirdi. Therefore, the present study explores the population status of vultures and nesting behavior of S. calvus at Dhorfirdi.

\section{METHODS AND MATERIALS}

\subsection{Study Area}

The study was conducted at Shuklagandaki Municipality (formerly Dhorfirdi VDC) located in Tanahun district of Gandaki Province. The municipality has 12 wards with total population of 48,456 (CBS, 2019). The average maximum and minimum temperature at Khairenitar Station, Tanahun in 2017 were $30^{\circ} \mathrm{C}$ and $17.5^{\circ} \mathrm{C}$ respectively and the average rainfall in 2017 was $2272 \mathrm{~mm}$ (Western Regional Climate Office, Pokhara, 2018 cited in Statistics Office Kaski, 2018).

Giddha refers "vulture" and base refers "habitat", thus the "Giddhabase" indicates vulture habitat. Geographically, Giddhabase is located at $28^{\circ} 04^{\prime} 10.014^{\prime \prime} \mathrm{N}$ and $84^{\circ} 02^{\prime} 02.052^{\prime \prime} \mathrm{E}$ at an altitude of 1023 $\mathrm{m}$ asl. It is located in ward no. 9 of Shuklagandaki Municipality that consist of 639 households with the total population of 2535 including $43.31 \%$ male and $56.69 \%$ female (CBS, 2019). It lies in Millennium Trekking Route (MTR) which is around $80 \mathrm{~km}$ long trail connecting Tanahun to Syangja. It begins from Dulegaunda of Tanahun (approximately $30 \mathrm{~km}$ east of Pokhara) to Majhkot of Syangja. The study was conducted in MTR at Dhorfirdi including Rastal, Magarnas, Giddhabase, Kharbari, Bajasthala and Dhorbarahi temple. MTR has great potential for tourism activities. It is situated between two Vulture Safe Feeding Sites i.e. Vulture Restaurant at Nawalparasi district (south of Tanahun district) and Ghachowk Vulture Restaurant at Kaski district (north of Tanahun district).

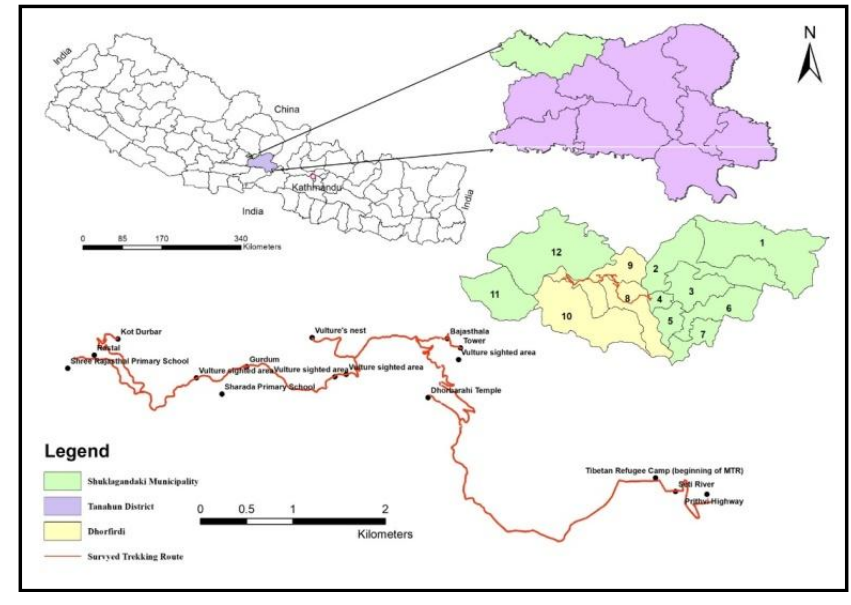

Figure1. Location map showing vulture sighted areas in MTR 


\subsection{Methodology}

The preliminary survey was carried out in July 2017 in which the MTR in Dhorfirdi was visited. Consultation meeting was conducted with ward chairperson, Forest User's Group, Women Group, teachers and local people. Initial visit identified vulture's nest in Kafaldanda-Bhardanda Community Forest at Kharbari.

\subsection{Population Status}

Population was counted along the MTR i.e. Rastal, Giddhabase, Kharbari, Bajasthala to Dhorbarahi temple at Dhorfirdi using a transect walk through line transect method. A transect line from Bajasthala to Rastal of $3.72 \mathrm{~km}$ long was surveyed.

Transect survey was conducted in summer (March) and winter (November), for one week of each season using binocular, camera, GPS, checklist and questionnaire. Population count was conducted from 7 am to $11 \mathrm{am}$ and $3 \mathrm{pm}$ to $6 \mathrm{pm}$ as vultures were found to be active during the times. During the transect walk, GPS coordinates of the vulture sightings were noted. A simple checklist was developed. Questionnaire was conducted with the local people in the settlements along the trail in MTR based on history of vulture's existence, species of vultures, trend of population change, habitat and feeding. To avoid duplication, population was counted at the same time in different locations of the transect by different people.

\subsection{Nesting Behavior}

Focal animal sampling/scan sampling suggested by Altman, 1974 was used to monitor the arrival and departure of the birds by using Bushnell, $8^{*} 42$ binocular. Scan sampling was conducted continuously for two out of every seven minutes. Thus, the method includes two minutes of scan followed by five minutes of interval during which no observations were made until the next scan begins from 6:30 am to 5:30 pm. Data was collected for 7 days between 10th to 16th March 2018.

Each scan period consist of two minutes of direct observation with 95 scans per day. It was continued for seven days which summed to 1330 minutes in total in study location during incubation stage. It is represented as:

95 scan $* 2$ minutes $* 7$ days $=1330$ minutes

A pair of S. calvus in a nest was observed as only a single nest was found in the study site. With the time of arrival of birds in and departure of birds from the nest, the presence or absence of the parent were recorded. Also, the activities performed by the vultures in the nest during its incubation were recorded. Nesting behavior was observed from distance of $500 \mathrm{~m}$ from the nesting tree, without disturbing the birds. A simple format was developed for noting the behavior of vultures. Photographs were taken using a DSC$\mathrm{H}^{*} 200 \mathrm{~V}$ Sony digital camera and $30 *$ lens magnification.

Information regarding the nesting characteristics such as geographical coordinate, location of nest, approximate height of nesting cliff/tree and nest, length and width of nest, materials used for nest construction, period of nesting, place selected for nesting and activity of parent birds were recorded.

\subsection{Data Analysis}

Primary data regarding population status and behaviour of vultures were compiled and analyzed using Microsoft Excel version 16 and were presented in graph and table. GIS 10.5 software was used for preparation of location map.

The frequency of each categories of behaviour was calculated by dividing the number of observations of the particular behaviour by the total number of observations. The analysis was based on the behaviors recorded as presented in Table 1. 
Population Status and Nesting Behavior of Red-Headed Vultures (Sarcogyps Calvus) at Dhorfirdi, Tanahun District, Nepal

Table1. Description of the nesting behavior (activities) of S. calvus

\begin{tabular}{|c|c|c|}
\hline S.N. & Behaviors & Description \\
\hline 1 & Head movement & movement and turning of head in all direction \\
\hline 2 & Resting & wings wrapped by sitting in nest without closing eyes \\
\hline 3 & Preening & slightly scratching the body parts with the help of bill \\
\hline 4 & Sleeping & resting by closing eyes \\
\hline 5 & Change of shift & one vulture flying away from nest and incubation by next vulture \\
\hline 6 & Turning of egg & other behaviours than above \\
\hline 7 & Others & \\
\hline
\end{tabular}

\section{RESULT}

\subsection{Population}

\subsubsection{In Summer}

During the transect survey, vultures were sighted in four different locations i.e. Bajasthala, Kharbari, Gurdum and Magarnas. Habitat of S. calvus was found at Kharbari (Kafaldanda-Bhardanda Community Forest). Altogether, six species of vultures were sighted in summer namely, Gyps himalayensis, Gyps fulvus, Neophron percnopterus, G. bengalensis, G. tenuirostris and S. calvus.

Altogether 96 vultures were recorded in summer including G. himalayensis (27), G. fulvus (26), N. percnopterus (22), G. bengalensis (7), G. tenuirostris (2) and S. calvus (12). Out of the total vultures, 9 vultures were sighted at Magarnas, 42 at Gurdum, 31 at Bajasthala and 14 at Kharbari. Population of G. himalayensis was found to be highest (27) and G. tenuirostris was found to be lowest (2) in summer (Table2).

Table2. Population status of vulture in summer

\begin{tabular}{|c|c|c|c|c|}
\hline S.N. & Date & Location & Type of vulture & Number \\
\hline \multirow{4}{*}{1} & \multirow{4}{*}{$3 / 10 / 2018$} & Magarnaas & G. himalayensis & 3 \\
\hline & & Gurdum & G. fulvus & 2 \\
\hline & & \multirow[t]{2}{*}{ Bajasthala } & G. himalayensis & 2 \\
\hline & & & G. fulvus & 1 \\
\hline \multirow{2}{*}{2} & \multirow{2}{*}{$3 / 11 / 2018$} & Magarnaas & G. himalayensis & 6 \\
\hline & & Gurdum & N. percnopterus & 1 \\
\hline \multirow{5}{*}{3} & \multirow{5}{*}{$3 / 12 / 2018$} & \multirow[t]{3}{*}{ Gurdum } & G. himalayensis & 1 \\
\hline & & & G. bengalensis & 1 \\
\hline & & & S. calvus & 2 \\
\hline & & Kharbari & N. percnopterus & 3 \\
\hline & & Bajasthala & N. percnopterus & 2 \\
\hline \multirow{2}{*}{4} & \multirow{2}{*}{$3 / 13 / 2018$} & \multirow[t]{2}{*}{ Kharbari } & N. percnopterus & 4 \\
\hline & & & S. calvus & 2 \\
\hline \multirow{6}{*}{5} & \multirow{6}{*}{$3 / 14 / 2018$} & \multirow[t]{5}{*}{ Gurdum } & G. himalayensis & 4 \\
\hline & & & G. fulvus & 4 \\
\hline & & & N. percnopterus & 7 \\
\hline & & & G. bengalensis & 2 \\
\hline & & & S. calvus & 2 \\
\hline & & Kharbari (vulture's habitat) & S. calvus & 2 \\
\hline \multirow{6}{*}{6} & \multirow{6}{*}{$3 / 15 / 2018$} & \multirow[t]{6}{*}{ Bajasthala } & G. himalayensis & 4 \\
\hline & & & G. fulvus & 11 \\
\hline & & & N. percnopterus & 2 \\
\hline & & & G. bengalensis & 1 \\
\hline & & & G. tenuirostris & 2 \\
\hline & & & S. calvus & 1 \\
\hline
\end{tabular}


Population Status and Nesting Behavior of Red-Headed Vultures (Sarcogyps Calvus) at Dhorfirdi, Tanahun District, Nepal

\begin{tabular}{|c|c|c|c|c|}
\hline S.N. & Date & Location & Type of vulture & Number \\
\hline & & Gurdum & G. himalayensis & 5 \\
\hline & & & G. fulvus & 2 \\
\hline & & & G. bengalensis & 2 \\
\hline \multirow{8}{*}{7} & \multirow{8}{*}{$3 / 16 / 2018$} & \multirow[t]{3}{*}{ Gurdum } & G. fulvus & 4 \\
\hline & & & N. percnopterus & 2 \\
\hline & & & S. calvus & 1 \\
\hline & & \multirow[t]{2}{*}{ Kharbari } & G. bengalensis & 1 \\
\hline & & & S. calvus & 2 \\
\hline & & \multirow[t]{3}{*}{ Bajasthala } & G. himalayensis & 2 \\
\hline & & & G. fulvus & 2 \\
\hline & & & N. percnopterus & 1 \\
\hline
\end{tabular}

\subsubsection{In Winter}

Vultures were sighted at Bajasthala, Kharbari, Gurdum and Magarnas. Also, information was obtained that, vultures were sighted at Rastal by the locals. All species of vultures found in summer except G. himalayensis and G. tenuirostris were found in winter.

Altogether 46 vultures were recorded in winter including G. fulvus (18), N. percnopterus (9), G. bengalensis (12) and S. calvus (7). Out of the total vultures, 2 vultures were sighted at Magarnas, 18 at Gurdum, 14 at Bajasthala and 12 at Kharbari. Vultures were observed flying in the sky. Population of G. fulvus was found to be highest (18) and S. calvus was found to be lowest (7) in winter (Table3).

Table3. Population status of vulture in winter

\begin{tabular}{|c|c|c|c|c|}
\hline S.N. & Date & Location & Type of vulture & Number \\
\hline \multirow{2}{*}{1} & \multirow{2}{*}{$11 / 11 / 2018$} & Gurdum & G. bengalensis & 1 \\
\hline & & Kharbari & G. fulvus & 2 \\
\hline \multirow{4}{*}{2} & \multirow{4}{*}{$11 / 12 / 2018$} & \multirow[t]{2}{*}{ Gurdum } & N. percnopterus & 2 \\
\hline & & & G. bengalensis & 2 \\
\hline & & Magarnas & G. fulvus & 2 \\
\hline & & Bajasthala & G. bengalensis & 1 \\
\hline \multirow{4}{*}{3} & \multirow{4}{*}{$11 / 13 / 2018$} & \multirow[t]{2}{*}{ Gurdum } & G. fulvus & 2 \\
\hline & & & N. percnopterus & 1 \\
\hline & & Kharbari & N. percnopterus & 2 \\
\hline & & Bajasthala & G. bengalensis & 2 \\
\hline \multirow{5}{*}{4} & \multirow{5}{*}{$11 / 14 / 2018$} & Gurdum & S. calvus & 2 \\
\hline & & \multirow[t]{2}{*}{ Kharbari } & G. fulvus & 2 \\
\hline & & & N. percnopterus & 1 \\
\hline & & \multirow[t]{2}{*}{ Bajasthala } & G. fulvus & 2 \\
\hline & & & G. bengalensis & 1 \\
\hline \multirow{5}{*}{5} & \multirow{5}{*}{$11 / 15 / 2018$} & \multirow[t]{2}{*}{ Gurdum } & G. bengalensis & 2 \\
\hline & & & S. calvus & 1 \\
\hline & & \multirow[t]{2}{*}{ Kharbari } & G. fulvus & 1 \\
\hline & & & N. percnopterus & 1 \\
\hline & & Bajasthala & S. calvus & 1 \\
\hline \multirow{5}{*}{6} & \multirow{5}{*}{$11 / 16 / 2018$} & \multirow[t]{2}{*}{ Gurdum } & G. fulvus & 2 \\
\hline & & & G. bengalensis & 2 \\
\hline & & Kharbari & S. calvus & 2 \\
\hline & & \multirow{2}{*}{ Bajasthala } & G. fulvus & 3 \\
\hline & & & N. percnopterus & 1 \\
\hline \multirow{4}{*}{7} & \multirow{4}{*}{$11 / 17 / 2018$} & Gurdum & S. calvus & 1 \\
\hline & & Kharbari & G. bengalensis & 1 \\
\hline & & \multirow[t]{2}{*}{ Bajasthala } & G. fulvus & 2 \\
\hline & & & N. percnopterus & 1 \\
\hline
\end{tabular}




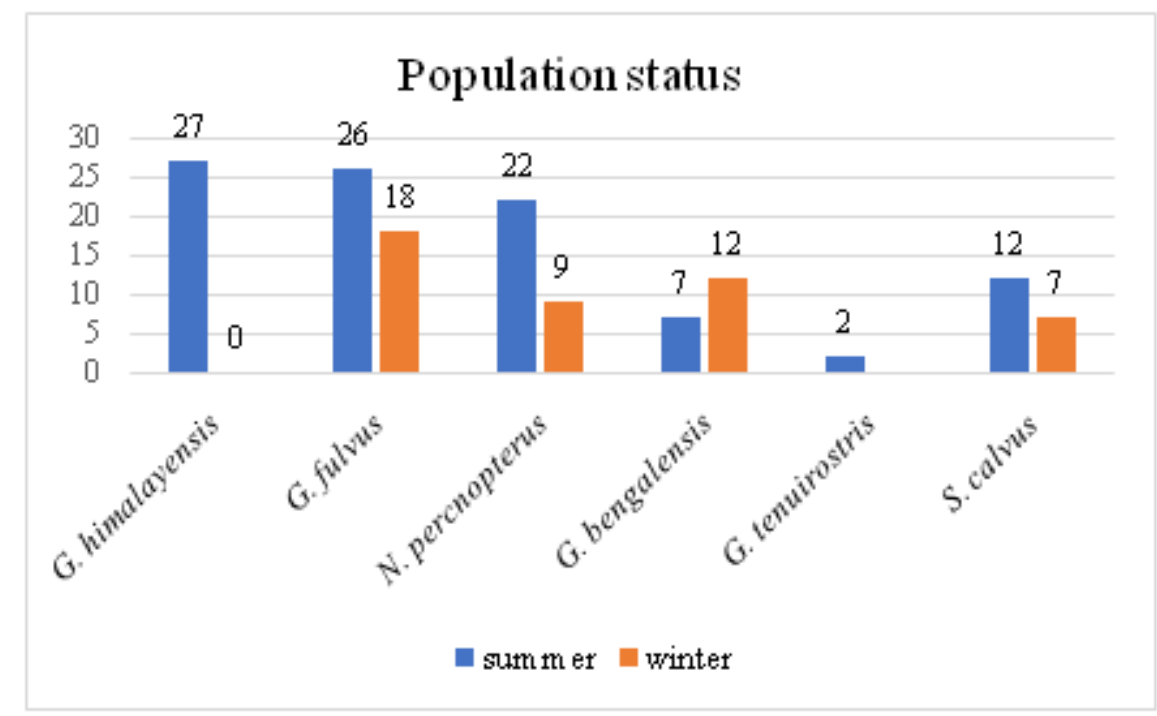

Figure2. Summer and winter vulture population

Vulture sightings were found relatively higher during summer (six species, 96 individual) as compared to winter season (four species, 46 individual). Seasonal variations were noticed higher in G. himalayensis when compared to other species found in the study area. Highest population was found at Gurdum in both summer and winter. Species diversity is found to be highest during summer season as compared to winter season.

\subsection{Nesting Behavior}

Nesting of S. calvus was observed in Simal (Bombax ceiba) located in Kafaldanda- Bhardanda Community Forest at $28^{\circ} 04^{\prime} 10.9^{\prime} ' \mathrm{~N}$ and $84^{\circ} 02^{\prime} 02^{\prime} 02.3^{\prime}$ ' $\mathrm{E}$ with an elevation of $859 \mathrm{msl}$. Nest was in almost top of the tree $(24 \mathrm{~m})$ with a tree height of approximately $25 \mathrm{~m}$. The nest was elliptical in shape with an area of $17662.5 \mathrm{~cm}^{2}$ (225 cm of major axis and $100 \mathrm{~cm}$ of minor axis). The red flowers in nesting tree was found to be blooming without any leaves. Clutch size was one egg in nest that was observed during incubation. Approximately, 20 trees of B. ceiba were found around nesting area of vulture however, nest was found to be prepared only in a single tree.

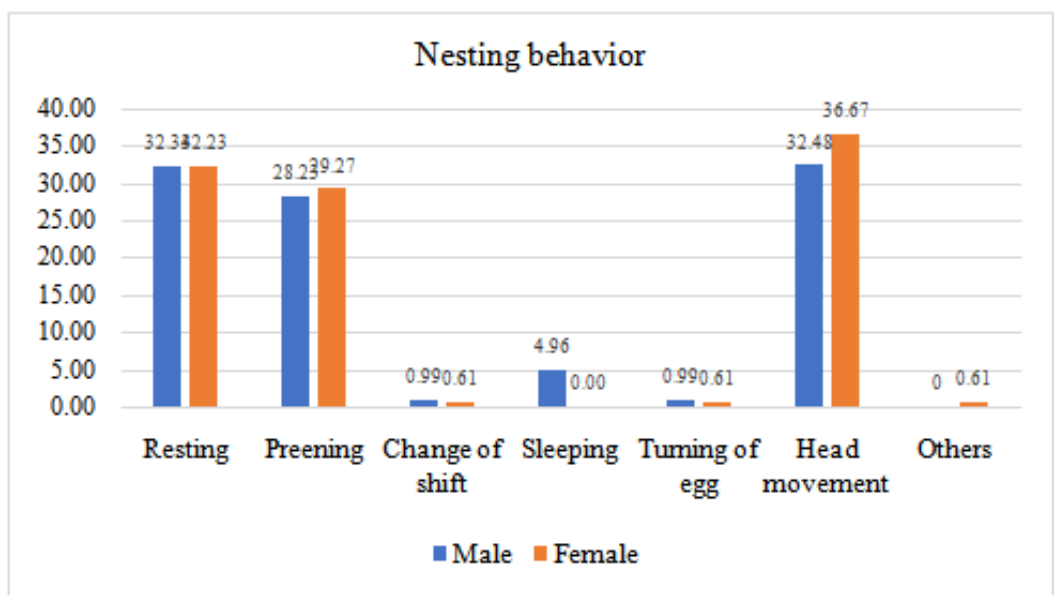

Figure3. Nesting behavior of S. calvus

During observation of nesting behavior in a single nest, the egg was covered with full protection. Different nesting behaviors were observed in vulture in which head movement (32.48\%) was found to be highest in male parent followed by resting $(32.34 \%)$, preening $(28.23 \%)$, sleeping $(4.96 \%)$, change of shift and turning of egg ( $0.99 \%$ each). Similarly, head movement was found to be highest $(36.67 \%)$ in 
female parent followed by resting $(32.23 \%)$, preening $(29.27 \%)$, change of shift and turning of egg $(0.61 \%$ each) and others $(0.61 \%)$.

\subsubsection{Resting}

Vultures moved away for foraging for about 3.5 to 4.5 hours during day time. After foraging, male and female parent vulture rested alternately in the nest and continued incubation.

\subsubsection{Preening}

Vultures rubbed their bill during incubation period.

\subsubsection{Change of shift}

In the morning, female parent was present incubating in the nest during the whole study period. Female parent moved away from the nest and return back in the afternoon after foraging during which the incubation was continued by male parent. Therefore, the incubation period was performed by change of shift. An egg was found to be incubated by a pair of vultures alternately one after another. Thereafter, both adults took turns in incubating, with one relieving the other at the nest.

The departing adult often anticipated the other's arrival by looking out from the nest. During the change of shift, when a mate arrived, both vultures observed the surrounding area for approximately 15 seconds. After that one of the vultures left the nest and remained in ready position for flight and flew away in about 15 seconds. Therefore, the vulture remained in the nest for approximately 30 seconds after the arrival of its mate. The incubation was continued by the next vulture (Figure4). The change of shift occured twice a day i.e. in the morning and in the afternoon. The egg was hatched successfully in the nest and the juvenile was in the stage of flying within the first week of March 2018(Figure 3.3).

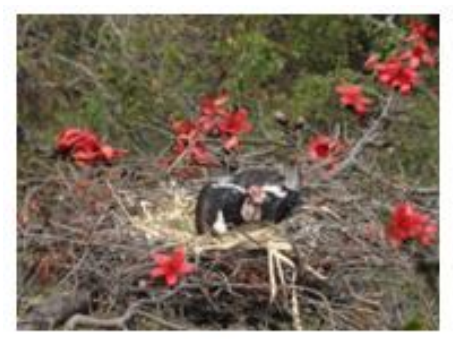

(a)

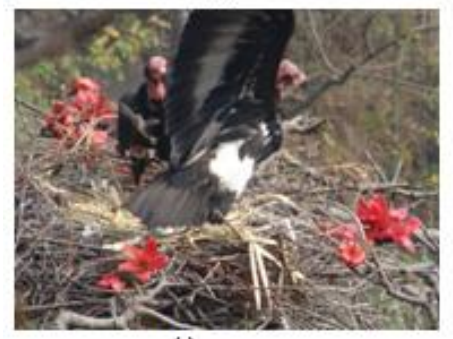

(c)

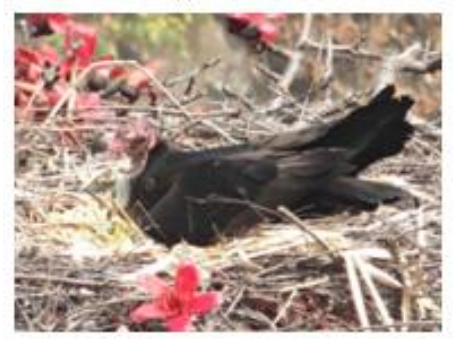

(e)

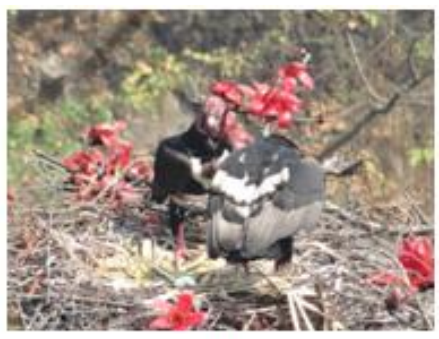

(b)

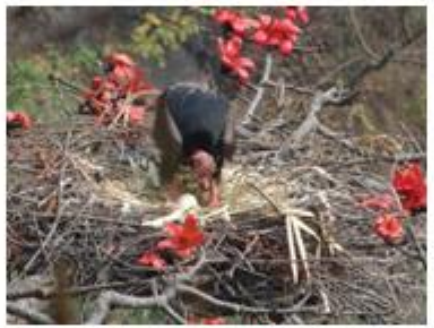

(d)

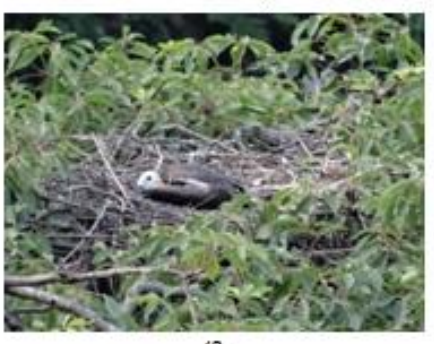

(f)

Figure4. Change of shift during incubation by a pair of vultures alternately one after another and successfully hatching of the egg shown by (a) incubation by female parent (b) arrival of male parent in the nest (c) change of shift by flying away of the female parent (d) turning of egg by male parent after foraging (e) continue incubation by the male parent as the female parent moves away (e) hatching of egg into the juvenile S. calvus in the nest 


\subsubsection{Sleeping}

Sleeping behavior was observed only in male parent during the study period i.e. 6:30 am to 5:30 pm from 10th to 16th March 2018. However, it was not observed in female parent.

\subsubsection{Turning of Egg}

Parent vulture started incubating once their partner left the nest. During the change of shift, the incoming adult rolled and replaced the egg with its bill. And continued incubation. It was observed that every time the incubation began only after turning or positioning the egg with its bill. The incubation occurred within approximately two minutes of the mate's arrival.

\subsubsection{Head Movement}

During incubation, head movement was frequently observed in both male and female parent. They moved head whole day and observed the surrounding area during incubation. The vultures remained vigilant during incubation.

\subsubsection{Others}

The other behavior such as standing and changing position/direction during incubation were observed in the morning time between 7:40-11:10 am. Only female parent showed other behaviors $(0.61 \%)$ than mentioned above.

\section{DISCUSSION}

\subsection{Population}

In the present study, six species of vultures have been recorded at Dhorfirdi including G. himalayensis, G. fulvus, N. percnopterus, G. bengalensis, G. tenuirostris and S. calvus. However, five species of vultures were recorded during study period in and around the vulture restaurant except G. fulvus at Pithauli, Nawalparasi (Adhikari \& Bhattarai, 2017), which is the closest habitat of vulture that lies in the south of Tanahun district. It indicates that, G. fulvus might have suitable habitat at Dhorfirdi or could have migrated from the Ghachowk Vulture Restaurant, Kaski which lies at the north west of Pokhara.

92 and 51 were the maximum and minimum population of $\mathrm{G}$. bengalensis recorded in the months of October and March respectively in the adjoining district i.e. Palpa (Rampur valley) that lies in the south of Tanahun district (Baral \& Gautam, 2007a). 36 G. bengalensis were recorded in the Pokhara valley during the 2006-07 field season including $21 \mathrm{G}$. bengalensis in March 2007. Also, 86 N. percnopterus were recorded in the Pokhara valley in 2006-07 including 14 G. tenuirostris in October 2006 and 43 N. percnopterus in March 2007 (Baral \& Gautam, 2007b). Likewise, the maximum number of 12 and 7 G. bengalensis were recorded at Dhorfirdi in the months of November (winter) and March (summer) respectively. 22 N. percnopterus were recorded in March and 2 G. tenuirostris in November. As Dhorfirdi lies in between Kaski (Pokhara valley) and Palpa, the vultures might have migrated from Kaski and Palpa.

Maximum number of vultures were recorded at Gurdum followed by Bajasthala and Kharbari both in summer and winter. As the nest of S. calvus was sighted at vulture's habitat at Kharbari, other habitat of vultures might be around Gurdum, Bajasthala and Kharbari.

Flock size of G. himalayansis was minimum in winter than that in summer at Arghakhanchi (Bhusal, 2011). G. himalayensis and A. monachus were winter visitors in Pokhara Valley (Baral \& Gautam, 2007b). However, G. himalayansis was recorded highest in the study in summer which might be due to its relatively high density or its migration from high elevation area such as Mustang. The occurance of least number of $\mathrm{S}$. calvus in winter could be due to their territorial behavior.

\subsection{Nesting Behavior}

Vulture normally prefers nesting site at the edges of forests, open grassland or lone silk cotton tree and lightly wooded old forests (Giri \& G.C., 2002). 
S. calvus was found to built nest at the top of a large tree having an average height of $27 \mathrm{~m}$ from the ground level. One active nest of S. calvus was recorded in Adina cordifolia tree at Tansen Municipality12, Dharampani and another in Pinus tree at Baugha Pokharathok-6, Luhung (Bhusal \& Paudel, 2016). In the present study, vulture nested in one of the B.ceiba tree with 20 B.ceiba trees in surrounding. Nest was prepared in undisturbed area from the human settlement in a tall tree having $25 \mathrm{~m}$ height and $111 \mathrm{~cm}$ DBH. Red-headed Vultures nests are found solitary. According to the local resource person, vulture nested in same tree for last 20 years. As per the study conducted by (Paudel \& Bhusal, 2015), the nest of S. calvus was found in the trunk of Pinus roxburghii with $100 \%$ breeding success. Therefore, vultures prefer tall trees for nesting so that they can easily observe the surrounding area and protect their nest from predators.

The large, flat nest was constructed from sticks and lined towards the centre with leaves and dry grass (Bhusal \& Paudel, 2016). Sinha et al., 2017 found nest of S. calvus was constructed from sticks facing the center with leaves and dry grass. In the present study, nest was elliptical structure having two layers. First lower layer consist large hard and dry stems of the plant while second upper layer was made up of smaller and soft leaves of plants and grasses. Second layer was constructed in the middle of the nest where incubation was taken place.

The study on the nesting behavior of S. calvus was not found. Therefore, it has been compared with G. bengalensis. The daily activity of G. bengalensis includes feeding, scratching, sunning, reaction to disturbance, flight and fight. This bird spends maximum time in resting and flight (Khatri, 2016). In the present study, although the activities during nesting of vulture were resting, preening, head movement, turning of egg and others, the major behaviors observed during incubation were head movement, resting and preening.

\subsubsection{Preening}

Preening behavior is seen in N. percnopterus for removal of dirt and debris of the body surface (Mishra et al., 2018). However, in the present study, preening behavior was frequently observed after head movement and resting in both vultures which might be to clean their body and bill and keep their bill in good shape.

\subsubsection{Change of Shift}

When exchanging duties by Griffon vultures at the nest no special behavior such as greeting or body posture was recorded between the partners apart from the erected scapular feathers of the mates when they met at the nest (Xirouchakkis \& Mylonas, 2007) during incubation shift. Similar case was found in the present study. The vulture left the nest soon after the arrival of the mate.

Change overs occurred in the morning, before a day's foraging, or in the afternoon after foraging (Robertson, 1986). This was similar to the present study in which, the change of shift occurred twice a day i.e. in the morning and in the afternoon. S. calvus laid only one egg during one breeding season and both male and female took part in incubation and provide parental care (Bhusal \& Paudel, 2016). Until the chick reached the fledgling stage, at least one of the parent's vultures was regularly found to care the chick sitting on tree (Subedi, 2009). This is similar to the pair of S. calvus in Dhorfirdi, as the vulture lay only a single egg in a year. There was an equal contribution of the both vultures in incubation. Also, one of the parent's vulture was found around the tree until the chick could not fledged out from the tree.

\subsubsection{Turning of egg}

The incoming adult roll the egg out of the cup by standing on the rim after a few feeble (Robertson, 1986). Likewise, in the study, the vulture arrived, rolled and replaced the egg with its bill and thereafter, continued to incubate. Therefore, turning of eggs during incubation with the bill helps in maintaining the temperature of egg that leads to successful nesting behavior reducing the possibility of mortality of embryo. 


\subsubsection{Head movement}

Both of the vultures remained alert and moved the head frequently whole the day to protect their egg and nest from predators. Therefore, head was turned in all directions for checking out the predators.

\subsubsection{Others}

Other behavior such as standing and changing position/direction during incubation were observed only in female parent. Sleeping behavior is seen only in male parent. These behavior might indicate that, female parent remains more in the nest so they need to change position than male and more alert than male parent.

\section{CONCLUSION}

Altogether six species of vultures were recorded in MTR i.e. G. himalayensis, G. fulvus, N. percnopterus, G. bengalensis, G. tenuirostris and S. calvus in which all were recorded in summer and four species were recorded in winter. Vultures were sighted at Bajasthala, Kharbari, Gurdum and Magarnas at Dhorfirdi along MTR.

The nest of S. calvus was observed at Kafaldanda-Bhardanda Community Forest at vulture's habitat in B. ceiba. The nest was solitary. A single egg was laid, with both parents shifting incubation duties. During the shift of incubation duties, the incubation began only after turning or positioning the egg with its bill. The activities during incubation of vulture were resting, preening, head movement, turning of egg and others, in which head movement, resting and preening were the major activities observed. There was an equal contribution of both vultures in incubation.

\section{ACKNOWLEDGEMENT}

We would like to acknowledge Nature First Nepal, The Rufford Foundation \& Lumbini Environmental Services Pvt. Ltd. for funding and IDEA WILD for providing equipments for the project. We would like to acknowledge Dr. Wendy Wright, Dr. Achyut Aryal, Mr.Bishnu Prasad Shrestha \& Mr. Ganesh Paudel for their guidance \& Mr. Bijay Maharjan, Ms. Sarita Lawaju, Mr. Arjun Subedi and Ms. Anju Koirala for their assistance during this research. We would like to thank Bird Consrvation Nepal for supporting the posters, pamphlets and books. Also, we would like to thank Department of Forests and Soil Conservation for providing permission for this research, Division Forest Office Tanahun, Tinkhole Community Forest Tanahun for their kind cooperation throughout this study. Last but not least we would like to thank Mrs. Sita Rana, for providing homely environment at her residents throughout this project.

\section{REFERENCES}

[1] Adhikari, J., \& Bhattarai, B. P. (2017). Can Vulture Restaurant Protect Critically Endangered Species of Vultures in Lowland Nepal? International Journal of Science and Research (IJSR), 2319-70.

[2] Baral, N., \& Gautam, R. (2007a). Population Status and Breeding Success of Whiterumped Vulture Gyps bengalensis in Rampur, Syanja and Tanahu, Nepal.

[3] Baral, N., \& Gautam, R. (2007b). Ecological Studies on Three Endangered Vulture Species.

[4] BCN, DNPWC. (2011). The State of Nepal's Birds 2010. Kathmandu: Bird Conservation Nepal and Department of National Park and Wildlife Conservation.

[5] Bhusal, K. (2011). Population Status and Breeding Success of Himalayan Griffon, Egyptian Vulture and Lammergeier in Gherabhir, Arghakhanchi, Nepal.

[6] Bhusal, K. P., \& Poudel, K. (2016). Distribution and breeding ecology of Red-headed Vulture Sarcogyps calvus in Nepal. 25.

[7] CBS. (2019, 03 27). Provincial Statistic. Retrieved from Central Bereau of Statistics: https://cbs.gov.np/province-statistics/

[8] DNPWC/MoFSC/GoN. (2009). Vulture Conservation Action Plan for Nepal.

[9] Giri, J. B., \& G. C., S. (2002). Study of vultures in Western Lowland of Nepal.

[10] IUCN. (2016). Vultures of Pakistan. Baanhn Beli, IUCN Pakistan. 
[11] Jerath, N., Ladhar, S. S., Singh, G., \& Singh, R. (Eds.). (2015-16). Vulture: An Endangered Bird. 13. Punjab ENVIS Centre.

[12] Kanaujia, A., \& Kushwaha, S. (2013). Vulnerable Vultures of India: Population, Ecology and Conservation. Rare Animals of India, 113-144.

[13] Khadka, K. K., \& Mandal, R. K. (2013). Understanding the Efficacy of Diclofenac Use-ban and its Aftermath Effect on Gyps Vulture in Koshi Tappu Wildlife Reserve, Nepal. Journal of Entomology and Zoology Studies, 1(4), 20-22.

[14] Khatri, P. C. (2016). The Ecology and Behaviour of Critically Endangered White-Rumped Vulture (Gyps Bengalensis) in and around Jorbeer Area, Bikaner. International Journal of Research in Environmental Science (IJRES), 2(4), 35-59.

[15] Mishra, S., Kumar, A., \& Kanaujia, A. (2018). Egyptian Vulture - Vanishing Fast.

[16] Paudel, K., \& Bhusal, K. P. (2015). Ecological Monitoring and Conservation of Vultures in Jajarkot District, Nepal.

[17] Paudel, K., Galligan, T. H., Bhusal, K. P., Thapa, I., Cuthbert, R. J., Bowden, C. G., Shah, R., Pradhan, N. M. B. (2016). A decade of vulture conservation in Nepal. In Proceedings of the Regional Symposium on Vulture Conservation in Asia (pp. 39-45). Karachi, Pakistan.

[18] Poudel, K., Bhusal, K. P., Nepali, B., Sadaula, A., \& Chaudhary, I. P. (2014). Vulture Conservation in Nepal. Bird Conservation Nepal, Kathmandu.

[19] Robertson, A. S. (1986). Notes on the Breeding Cycle of Cape Vultures (Gyps coprotheres). 20(2).

[20] Sinha, A., Kumar, A., \& Kanaujia, A. (2017). Red-headed Vulture: A Solitary Scavenger. International Journal of Recent Scientific Research, 8(7), 18737-18741.

[21] Statistics Office Kaski. (2018). Rural Municipality/Municipality's Profile of Tanahun. Pokhara: Statistics Office.

[22] Subedi, P. (2009). Monitoring of Gyps species vulture in Nawalparasi district, Nepal. 18.

[23] Xirouchakkis, S. M., \& Mylonas, M. (2010). Breeding behaviour and parental care in the Griffon Vulture Gyps fulvus on the island of Crete (Greece). Ethology Ecology and Evolution, 1-26.

Citation: Tej Kumar Shrestha., et.al," Population Status and Nesting Behavior of Red-Headed Vultures (Sarcogyps Calvus) at Dhorfirdi, Tanahun District, Nepal”, International Journal of Research Studies in Zoology, vol. 5, no. 3, p. 22-32, 2019. DOI: http://dx.doi.org/10.20431/2454-941X.0503003.

Copyright: () 2019 Authors. This is an open-access article distributed under the terms of the Creative Commons Attribution License, which permits unrestricted use, distribution, and reproduction in any medium, provided the original author and source are credited. 